\title{
Genetic mapping of the tomato quality traits brix and blossom-end rot under supplemental LED and HPS lighting conditions
}

\author{
Aina E. Prinzenberg $(\mathbb{D} \cdot$ Hanneke van der Schoot • Richard G. F. Visser $(\mathbb{D} \cdot$ \\ Leo F. M. Marcelis (i) - Ep Heuvelink (iD) - Henk J. Schouten $(\mathbb{D}$
}

Received: 1 April 2021 / Accepted: 29 October 2021/Published online: 12 November 2021

(C) The Author(s) 2021

\begin{abstract}
LED lighting has emerged as alternative to the current HPS standard in greenhouse production. However little is known about the impact on fruit quality under the different light spectra. We grew a biparental tomato RIL population between September 2019 and January 2020 under two commercial greenhouse supplemental lighting conditions, i.e. HPS, and $95 \% \mathrm{red} / 5 \%$ blue- LED, of about $220 \mu \mathrm{mol} \mathrm{m}{ }^{-2} \mathrm{~s}^{-1}$ at maximum canopy height for $16 \mathrm{~h}$ per day. Differences in Brix and blossom-end rot (BER) between the two light conditions were observed and we studied the genetic influences on those traits, separating genetics located on chromosomes from genetics located in plastids. The Brix value was on average $11 \%$ lower under LED than under HPS supplemental lighting. A LED-light specific QTL for Brix was identified on chromosome 6. This QTL can be of interest for breeding for tomato varieties cultivated under LED
\end{abstract}

Supplementary Information The online version contains supplementary material available at https://doi.org/10.1007/ s10681-021-02946-1.

A. E. Prinzenberg - H. van der Schoot .

R. G. F. Visser · H. J. Schouten ( $\square)$

Plant Breeding, Wageningen University and Research, PO Box 386, 6700 AJ Wageningen, The Netherlands e-mail: henk.schouten@wur.nl

A. E. Prinzenberg - L. F. M. Marcelis - E. Heuvelink Horticulture and Product Physiology, Wageningen University and Research, PO Box 16,

6700 AA Wageningen, The Netherlands supplemental lighting. A Brix-QTL on chromosome 2 was found for both light conditions. In our study fewer plants developed BER under LED supplemental lighting than under HPS. We identified a novel genetic locus on chromosome 11 for the incidence of BER that lead to a difference in about $20 \%$ of fruits with BER. This genetic component was independent of the light.

Keywords Blossom-end rot · Brix $\cdot$ LED $\cdot$ Solanum lycopersicum · Natural variation $\cdot$ Light spectrum . QTL
Abbreviations
HPS High Pressure Sodium Lamps
LED Light-Emitting Diodes
$\mathrm{R} / \mathrm{B} \quad$ Red and blue LED lighting
BER Blossom-end rot
EC Electric conductivity
QTL Quantitative trait loci

\section{Introduction}

Blossom-end rot in tomato

Tomato fruit quality and total yield can be impacted by fruit physiological disorders. One common disorder is blossom-end rot (BER) that becomes visible as necrotic lesions at the blossom-end of the fruit starting about two to four weeks after anthesis (Olle and 
Williams 2017; Djangsou et al. 2019). In addition, BER can also develop inside the fruit and affect the seeds and pulp (Ho et al. 1999). Two major factors triggering BER have been discussed, i.e. a calcium deficiency in the fruit and abiotic stresses (Saure 2001; Djangsou et al. 2019). The latter can act indirectly on the calcium supply or lead to reactive oxygen species (ROS) accumulation that in turn can lead to membrane and cell damage (Mestre et al. 2012; Djangsou et al. 2019). Calcium deficiency is thought to occur in the distal side of the rapidly growing fruit and there leads to membrane instability, breakdown and subsequent tissue damage (Ikeda and Kanayama 2015). Environmental factors that induce BER include drought (Franco et al. 1999) or low oxygen supply to the roots in hydroponic culture (Tachibana 1991), salinity (Zhai et al. 2015), increased temperature, and light (Adams and Ho 1993). There is very little knowledge on the light spectrum effect on BER. Far red light absorbing films for greenhouse coverage were mentioned to reduce BER in tomato (Gruda and Tanny 2014). A strong genetic component is assumed as well, as natural variation for BER was identified with susceptible and less susceptible cultivars for BER (Ho et al. 1993, 1995). Also grafting on specific root stocks showed benefits to prevent BER (Fan et al. 2011; Latifah et al. 2020). An introgression line carrying a Solanum pennellii chromosomal segment on chromosome 8 in an S. lycopersicum background had less BER and a higher calcium and potassium content in the fruit than the $S$. lycopersicum parent (Uozumi et al. 2012). This appears to be the only quantitative genetic study on BER.

Light effect on fruit Brix and genetic studies

Another major factor in tomato fruit quality is the taste and nutritional value. One important estimate for that is the Brix. The Brix index represents the total soluble solids content, that is measured by means of transmissivity of the solution, and incorporates organic acids as well as carbohydrates (Helyes and Lugasi 2006). Brix increases with higher electric conductivity (EC) of the nutrient solution (Wu et al. 2004) and decreases with more water supply (Helyes et al. 2012). Additional red light during the night was found to slightly increase Brix in a cherry tomato (Lo et al. 2014). In other cultivars intercanopy lighting had no significant effect on Brix neither with $80 \%$ red and
$20 \%$ blue (Paponov et al. 2020) nor 95\% red and 5\% blue light-emitting diode (LED) lights (Dzakovich et al. 2015); however, intercanopy lighting with red and far red LEDs increased Brix (Kim et al. 2020). Natural variation in Brix was identified in several studies of tomato (Haydar and Islam 2007; Helyes et al. 2008), as well as quantitative trait loci (Paterson et al. 1990; QTL; Lecomte et al. 2004). Introgression lines of wild alleles that conferred higher Brix content either due to increased organic acids (Ikeda et al. 2013) or sucrose (Baxter et al. 2005) were developed. To our understanding there is presently no study on the light interaction on quantitative trait loci (QTL) for Brix though the natural variation and differing results of red light on different cultivars suggest a genetic component for the light effect.

We aimed to identify if there is a light spectra dependent genetic basis for fruit quality. To that end, we grew a tomato recombinant inbred lines (RIL) population under conventional high pressure sodium (HPS) and LED supplementary light conditions in greenhouse compartments to determine fruit quality traits, especially Brix. We observed a segregation of BER in the population with different severity in the two light treatments. A genetic study was performed to reveal quantitative trait loci for Brix as well as BER and to determine if the light factors have a differential impact on the different genotypes.

\section{Materials and methods}

Plant materials

An F5 RIL population was derived from reciprocal crosses of the parents Ailsa Craig and Kentucky Beefsteak (TR00021), hereafter abbreviated with "A $\sim \mathrm{K}$ ". Among the 148 individuals in the population 75 genotypes have Ailsa Craig as a mother and 73 plants Kentucky Beefsteak as a mother. The crossings between the parental genotypes and selfing of the F1 plants were performed at Wageningen University \& Research, whereas the RIL populations from the F2 populations were developed and genotyped (F4 generation) by Nunhems Netherlands B.V. The genotyping was done with 185 KASP markers (2.9\% of marker calls scored as heterozygous and were excluded from the QTL analysis). 
Plant growth conditions

For the phenotyping of the RIL populations, the plants were grown in glasshouses of Unifarm (Wageningen University and Research) between September 2019 and January 2020. The plants were sown, measured and harvested in eight batches spread over two weeks. The plants were pre-grown on ebb and flood tables for four and a half weeks under natural lighting (supplemented with approximately $100 \mu \mathrm{mol} \mathrm{m} \mathrm{m}^{-2} \mathrm{~s}^{-1}$ HPS light $16 \mathrm{~h}$ before sunset unless the outside global radiation was above $250 \mathrm{~W} \mathrm{~m}^{-2}$ ). Afterwards the plants were divided onto two compartments $(12 \mathrm{~m} \times 12 \mathrm{~m})$ planted in double rows (ca. 2.2 plants per $\mathrm{m}^{2}$ ) with drip irrigation. In each compartment the same set of 148 genotypes was grown with one replicate each as well as six replicates of each parent of the RIL population. A border row of plants was grown that was not measured (to avoid a border effect). The plants were kept at a height of approximately $2.5 \mathrm{~m}$ to ensure near equal supplemental light distribution for all genotypes. The two compartments differed in the supplemental lighting system, with an average of about $220 \mu \mathrm{mol} \mathrm{m} \mathrm{m}^{-2} \mathrm{~s}^{-1}$ supplemental lighting (measured at $2.5 \mathrm{~m}$ over ground on several spots per row within each compartment) of either $95 \%$ red and 5\% blue LEDs (Green Power LED top lighting module DR/B LB, $190 \mathrm{~W}$, Philips) or high pressure sodium lamps (HPS; Master green power, cgt $400 \mathrm{~W}$, Philips). The lamps hung at ca. $3.5 \mathrm{~m}$ over ground. Supplemental lighting was provided for $16 \mathrm{~h}$, ending at sunset. The plants were grown on stone-wool (Rockwool Grodan B.V., Roermond, The Netherlands), irrigated with nutrient solution: $\mathrm{NH}_{4} 1.2 \mathrm{mM}, \mathrm{K}$ $7.2 \mathrm{mM}$, Ca $4 \mathrm{mM}, \mathrm{Mg} 1.82 \mathrm{mM}, \mathrm{NO}_{3} 12.4 \mathrm{mM}$, $\mathrm{SO}_{4} 3.32 \mathrm{mM}$, P $1 \mathrm{mM}$, Fe $35 \mu \mathrm{M}$ (Fe-DTPA/ FeEDDHSA), Mn $8 \mu \mathrm{M}$, Zn $5 \mu \mathrm{M}$, B $20 \mu \mathrm{M}$, Cu $0.5 \mu \mathrm{M}$ and Mo $0.5 \mu \mathrm{M}$. The macronutrients were obtained from a mixture of fertilizers of Yara Benelux BV (Rotterdam-Vlaardingen, The Netherlands) and the micronutrients were from the Agrispoor product line of Horticoop BV (Bleiswijk, The Netherlands). The final $\mathrm{pH}$ was adjusted with $\mathrm{KOH}$ to be between 5.5 and 5.8 with an EC of $2.0 \mathrm{dS} \mathrm{m}{ }^{-1}$. The EC of the nutrient solution in the stone wool slab was on average $3.8 \mathrm{ds} \mathrm{m}^{-1}$ under HPS versus $3.2 \mathrm{ds} \mathrm{m}^{-1}$ under LED. If the air temperatures in the compartments dropped below ca. $22{ }^{\circ} \mathrm{C}$ (in a later stage of the experiment $24{ }^{\circ} \mathrm{C}$ ) during the supplemental lighting period or $19{ }^{\circ} \mathrm{C}$ outside the supplemental lighting time, the compartments were heated (in case of the LED supplemental lighting with heating pipes below the plants and above the lamps to compensate for the heat irradiance from the HPS lamps; the HPS compartment was only heated by pipes below the plants). The Photosynthetically Active Photon Flux Density (PPFD) from the sun was estimated from measured solar radiation outside the greenhouse. For the estimation of the sunlight inside the greenhouse, a transmissivity factor of 0.62 was used based on measurements. The measured solar radiation was corrected for the fact that ca $47 \%$ of the solar radiation is in the PPF range and $\mathrm{W} \mathrm{m}^{-2}$ was converted into $\mu \mathrm{mol} \mathrm{m} \mathrm{m}^{-2} \mathrm{~s}^{-1}$ by assuming that $1 \mathrm{~W} \mathrm{~m}^{-2}$ solar light equals $4.57 \mu \mathrm{mol} \mathrm{m}{ }^{-2} \mathrm{~s}^{-1}$ (McCree 1972; Britton and Dodd 1976). Average environmental conditions over the experimental growth period are given in Supplemental Table 1. Pollination was warranted by the placement of bumblebees (Koppert, biological systems) in the greenhouse compartments.

\section{Phenotyping}

Blossom-end rot was scored as the number of fruit with visual outside symptoms (Fig. 1) compared to the number of total mature fruits of each plant over the whole growth period.

Brix was determined on one healthy, mature fruit per genotype and light condition (with no visual symptoms of rot outside or inside the fruit) using a refractometer (PR-32 $\alpha$, ATAGO, Tokio, Japan). For the parents $6-11$ fruits (of up to 6 genotypic replicates) were measured per light condition for Brix and acidity with the PAL-BXIAcid3 (ATAGO, Tokio, Japan).

The fruit shape was scored visually with a numeric score from 0 to 3 , where 0 are round fruit and 3 are highly facetted fruits (Supplemental Figure 1). In case fruits were not clearly scorable in those four categories half score points (e.g. 0.5 or 1.5 ) were given.

At the end of the growth period initial symptoms of tobacco mosaic virus (TMV) were observed (curled leaves at the newly developing leaves in the top). However, there was no significant difference neither in $\operatorname{BER}(p$-value $=0.47)$ nor in Brix $(p$-value $=0.89)$ between plants with and without first TMV signs. 


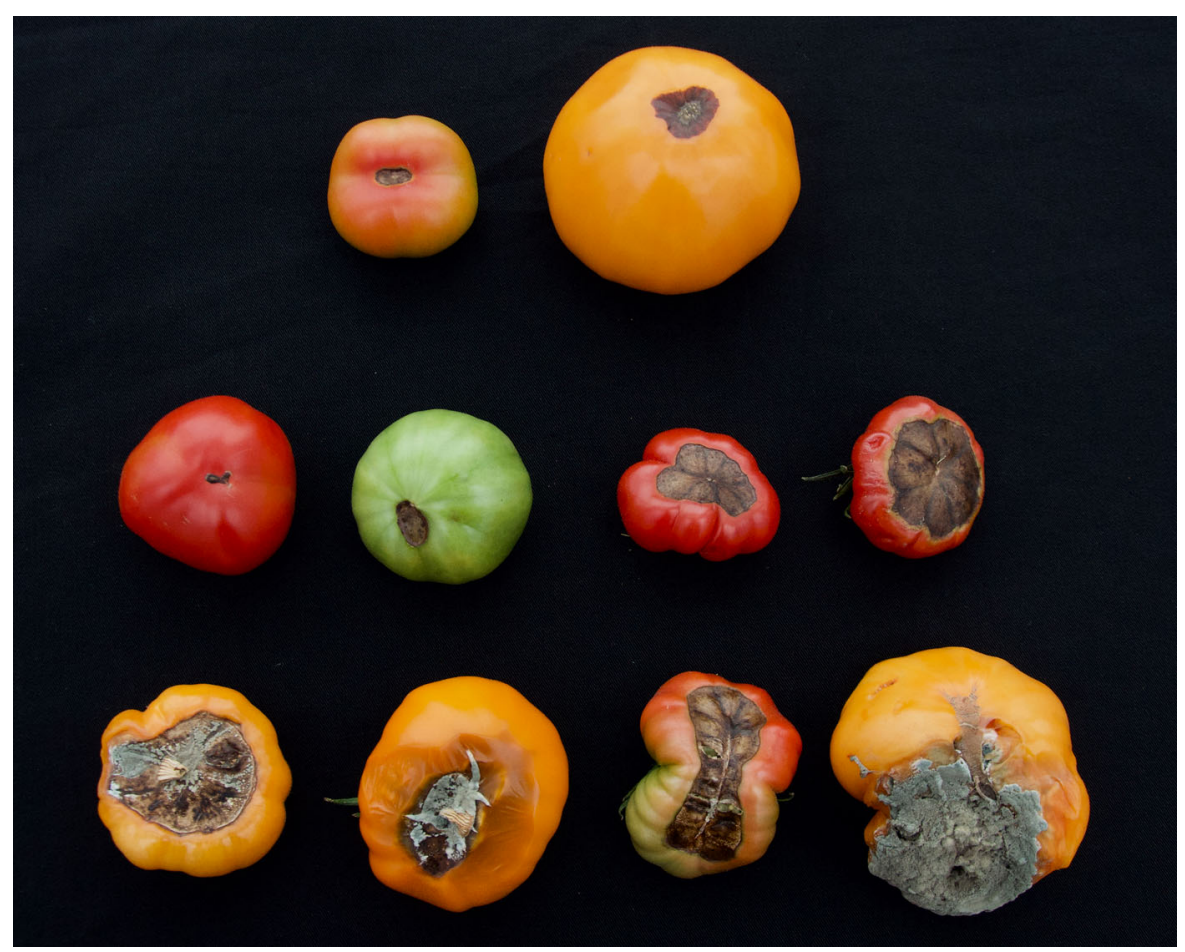

Fig. 1 Different stages of BER. (Examples of fruit with different severities of BER. The upper two fruits in the image show the parents 'Ailsa Craig' and 'Kentucky Beefsteak', and the following fruits are from RILs. The shown BER severity is

\section{Statistical analysis}

If not otherwise indicated, the statistical analysis was done using the basic statistics of $\mathrm{R}$ (version 3.5.0; www.r-project.org). Normality was tested with a Shapiro test and consecutively equal variance between both light conditions with an F-test. The Brix values of the RILs were normally distributed and showed equal variance between samples from the two light conditions. For this trait a paired t-test was used to test for light environment effects. For all other traits a Wilcox rank sum test was performed, as the difference of the pairs was not symmetrically distributed around the median of the pair-average and therefore did not fulfil the requirement for a signed rank sum test. The reciprocal cross group effect was tested per lightcondition. To test the environmental effect on the LED-specific QTL for Brix, an ANOVA was performed with the Car-package in $\mathrm{R}$ (version 3.0-0; Fox and Weisberg 2019). In this model, the allele scores at the peak marker of the QTL on chromosome 6 and the light conditions were interacting factors and the not representative for the respective genotypes. They are just shown exemplary. On the damaged tissue of some fruits fungi started to grow)

marker alleles of the QTL on chromosome 2 as additive factor. A post hoc Tukey test on the four haplotype groups (two parental alleles at QTL on chr. 2 and chr. 6) was done with the package Agricolae (version 1.3-2; De Mendiburu 2020). Average values in the text are, if not otherwise indicated, shown with their standard error of the mean. All graphics were made in $\mathrm{R}$, using the basic functions or with the package ggplot2 (version 3.0.0; Wickham 2016) or R/qtl (Broman et al. 2003). The genetic map was re-calculated for the RIL population based on the marker order provided by the company and a single QTL analysis was done with the package R/qtl (Broman et al. 2003), following Bowman and Sen (2009). This QTL analysis was done separately for the plants grown under HPS or LED light. For fruit form and percentage BER nonparametric interval mapping function was used with a LOD score threshold determined based on 1000 permutations. For Brix, the parametric QTL analysis was done with the in R/qtl implemented multiple imputation method (Sen and Churchill 2001). The LOD score threshold was calculated based on 1000 
permutations with 300 imputations for the estimation of the genotype probabilities. The explained variance of the QTL was estimated for all traits with the multiple imputation method. The size of the QTL regions were determined by an approximate 95\% Bayes credible interval (expanded to the closest markers). The number of candidate genes was predicted based on the SL2.5 tomato gene model using the tool Jbrowse of the Sol genomics network (solgenomics.net).

\section{Results}

BER under LED versus HPS supplemental lighting

Under LED slightly fewer plants were affected by BER; 20 out of 150 genotypes showed no or only up to $5 \%$ of BER while under HPS that were 32 genotypes (Fig. 2a). Of those genotypes showing BER, the percentage of fruits affected by BER (averaged over the genotypes) was $35 \% \pm 2 \%$ under LED light while this was $41 \% \pm 2 \%$ under HPS light. This difference was of low statistical significance though ( $p$-value $=$ 0.08). Considering the parents alone, there was no significant difference in the percentage of BER between them $(p>0.8)$ and although the BER was lower in both parents in LED light the difference between the conditions was not significant $(p>0.1)$. There was no marked difference between the reciprocal cross group of the RILs that contrasted regarding the maternally inherited plastids (in HPS $p=0.14$, in LED $p=0.04)$. A QTL analysis for the percentage of BER per genotype revealed a QTL on chromosome 11 at $8.3 \mathrm{Mb}$ (genome version SL2.5), present under both light conditions (Fig. 2b), explaining $11 \%$ or $12 \%$ (HPS or LED) of the variance. Genotypes with an Ailsa Craig allele at the QTL had on average $27 \% \pm 3 \%$ BER while genotypes with a Kentucky Beefsteak allele had $45 \% \pm 3 \%$ BER under HPS light $(20 \% \pm 3 \%$ vs. $37 \% \pm 3 \%$ under LED). Because the closest flanking markers around the peak QTL are further apart, the approximate 95\% Bayes credible interval of the QTL on chromosome 11 spans a region from ca 5.2 to $52.6 \mathrm{Mb}$ (with about 1300 annotated gene models). Therefore, a speculation of candidate genes is not done at this point.
Brix under LED versus HPS supplemental lighting

Brix and acidity were measured in the parents of the RIL population. The largest difference between the light conditions was found for the Brix value in the parent 'Ailsa Craig' with $4.9 \pm 0.28$ under HPS light and $3.8 \pm 0.08$ under LED light (p-value of 0.004). The acidity did hardly change between the conditions in the two genotypes, it may be slightly lower under HPS light for the parent 'Kentucky Beefsteak' ( $p$-value of 0.049; Supplemental Figure 2).

The Brix was scored for all RILs of the A $\sim \mathrm{K}$ population under HPS and LED light. On average the Brix was lower in the RILs growing under LED supplemental lighting, with $3.42^{\circ} \mathrm{Bx} \pm 0.04$, than under HPS supplemental lighting, with $3.84^{\circ} \mathrm{Bx} \pm$ 0.04 (Fig. 3a). The difference between the two light conditions was significant $(p$-value $<0.001$ ). There was no significant difference in Brix between the two reciprocal cross groups (in HPS $p=0.08$, in LED $p=0.35$ ). A QTL analysis revealed a QTL for Brix on chromosome 2 at $47.1 \mathrm{Mb}$ under HPS and $43.5 \mathrm{Mb}$ under LED (approximate 95\% Bayes credible interval: 43.5 Mb/41.4 Mb to 50.5 Mb) that was present in both lighting conditions explaining ca. $20 \%$ of the explained variance. For the plants grown under LED supplemental lighting there was an additional QTL on chromosome 6 at $44.6 \mathrm{Mb}$ (Fig. 3b; ca. $26 \%$ explained variance; approximate $95 \%$ Bayes credible interval: 43.7-47.1 Mb). An ANOVA model showed that this QTL on chromosome 6 is indeed LED specific, with a significant peak marker by light environment interaction $(p=0.035)$. Genotype groups with a combination of 'Ailsa Craig' alleles at the QTL on chromosome 2 and 'Kentucky Beefsteak' alleles on chromosome 6 had the highest average Brix value with $3.93^{\circ} \mathrm{Bx} \pm$ 0.07 which differed from the other three haplotype groups significantly at $p<0.05$. This Brix value was similar to the average Brix value under HPS light.

\section{Fruit form}

In the RIL population $\mathrm{A} \sim \mathrm{K}$ the fruit form segregated between the rounder type of the parent 'Ailsa Craig' and facetted 'Kentucky Beefsteak' form. The fruit form was scored from 0 as round to 3 as highly faceted. There was a highly significant correlation between the fruit form in the two light treatments ( $\mathrm{T}=0.64, p<0.001)$. Most of the genotypes that did 


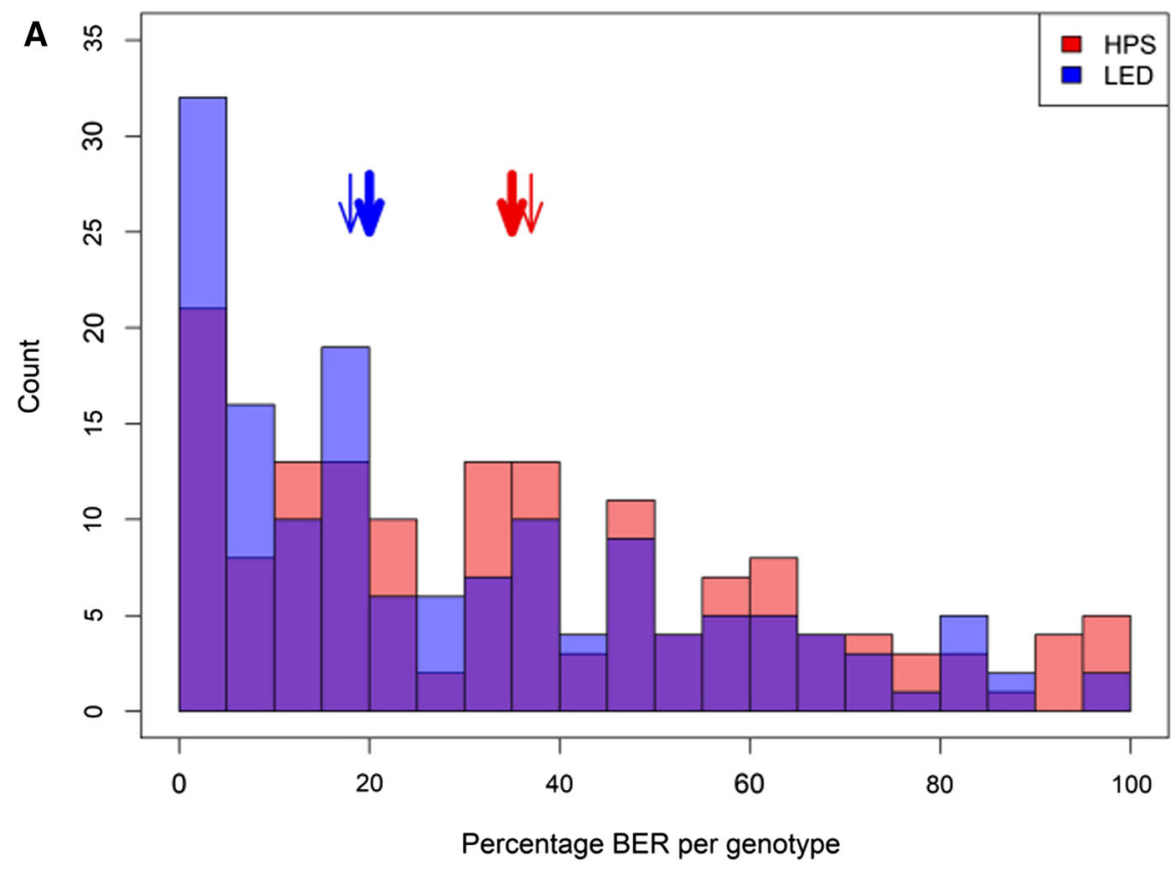

Percentage of blossom end rot

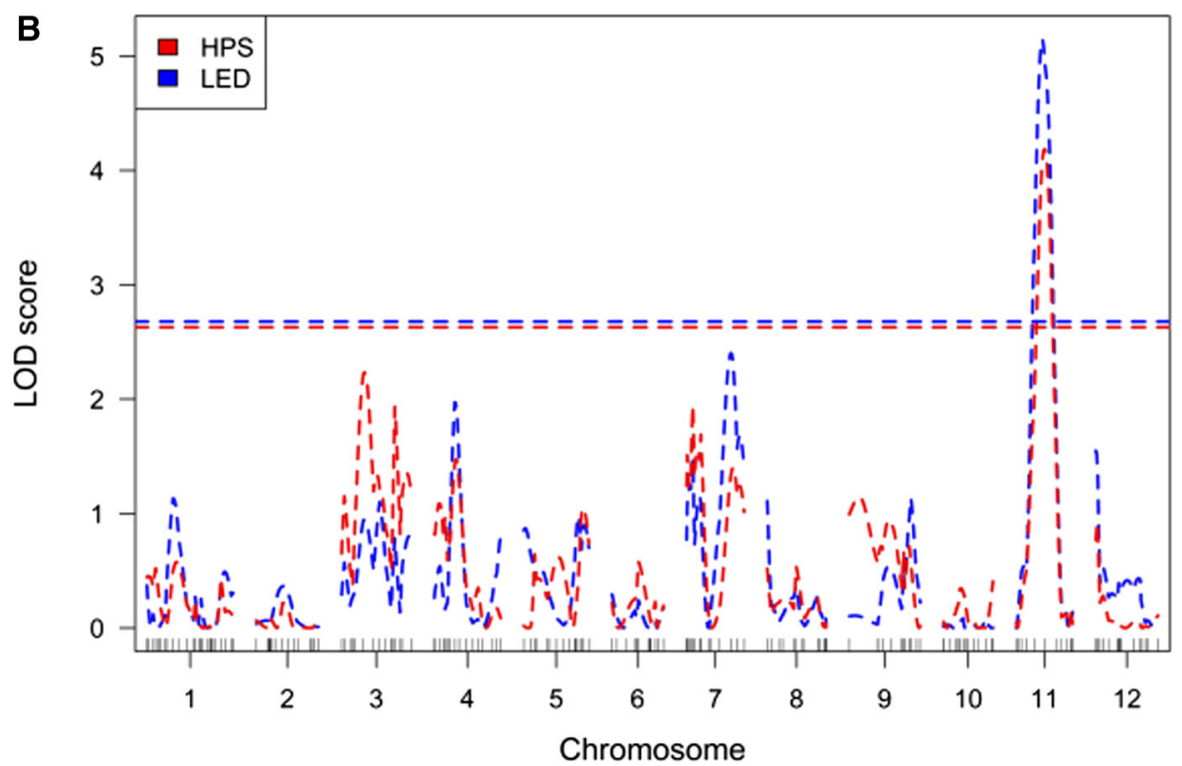

Fig. 2 BER in the RIL population under HPS and LED light. a The histograms show the distribution of the BER percentage per genotype over all genotypes in HPS (red) and LED (blue) light (a; where the two histograms overlap the area is depicted in lilac). The BER percentage of the parents of the RIL population, 'Ailsa Craig' (thick arrows) and 'Kentucky Beefsteak' (thin

not have an identical fruit form score in HPS and in LED were assigned as in between two categories or arrows), are indicated. b The LOD score of the QTL analysis for percentage of fruits with BER was done for both light conditions, HPS and LED supplemental lighting. The significance threshold for the LOD score is displayed as a horizontal dotted line

maximal one score category different. We consider this as experimental noise and therefore a non-relevant 


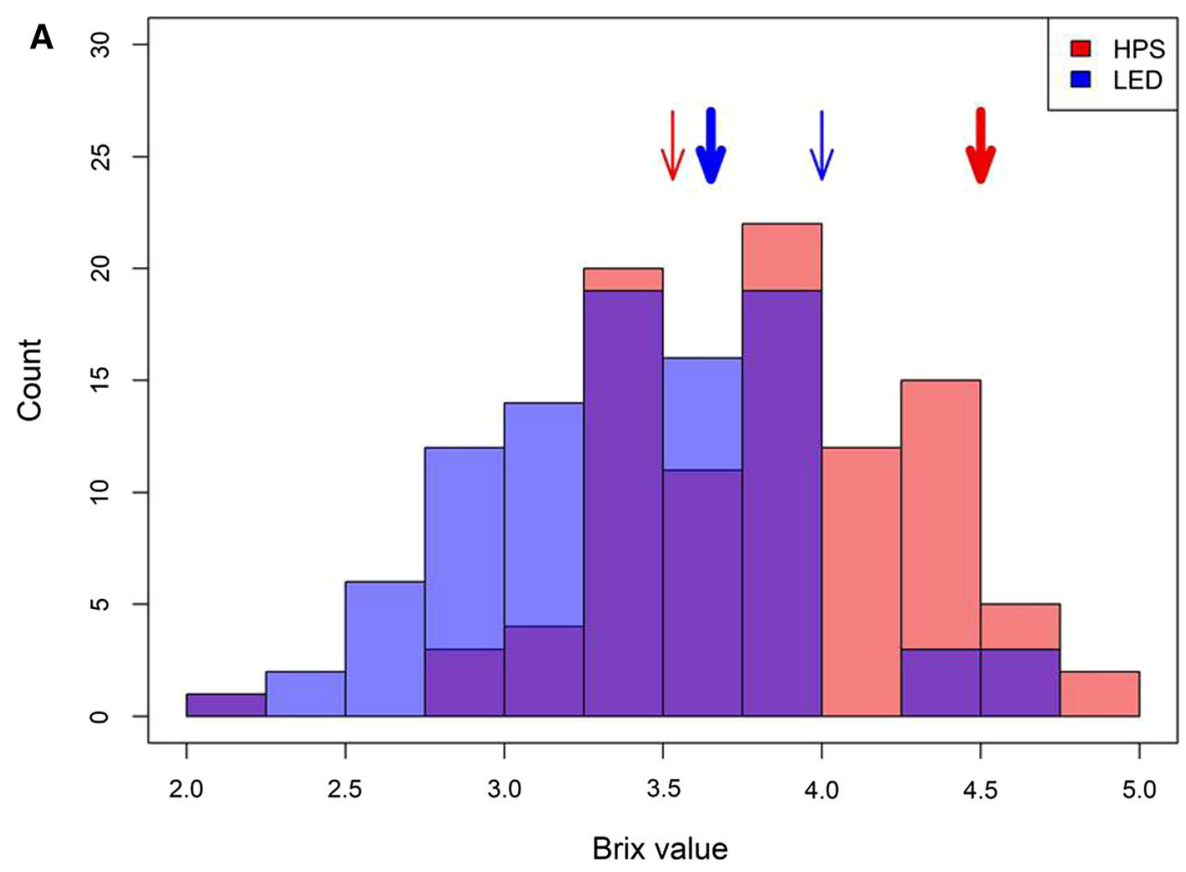

Brix value

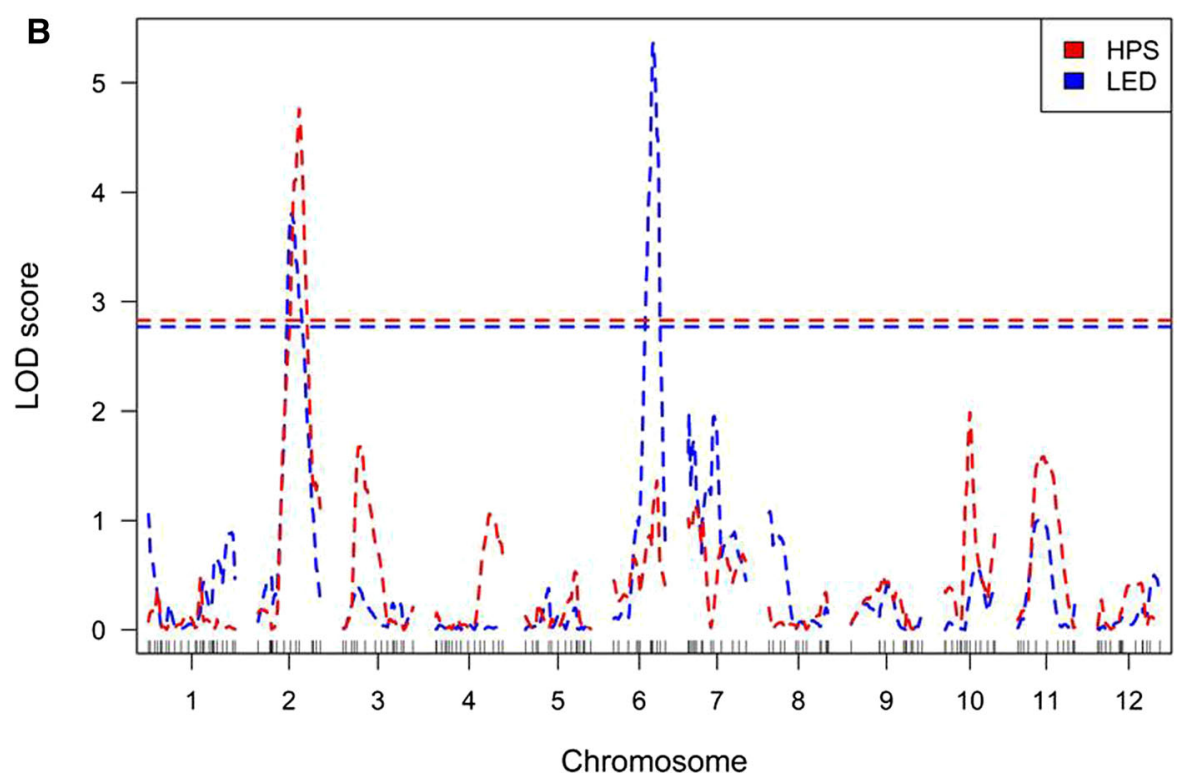

Fig. 3 Brix in the RIL population under HPS and LED light. a. Histograms show the distribution of the Brix value over all genotypes in HPS and LED light, depicted in red or blue respectively. The Brix value of the parents of the RIL

difference. Therefore, we conclude that we did not find a significant effect of supplemental lighting on fasciation. population, 'Ailsa Craig' (thick arrows) and 'Kentucky Beefsteak' (thin arrows), are indicated. b The QTL analysis shows differences in genetics for Brix between the light conditions, revealing a LED specific QTL on chromosome 6

QTL analysis was performed and a QTL with a high LOD score on chromosome 11 and a smaller one on chromosome 2 were identified for both light treatments (Supplemental Figure 3). The QTL span a 
region from ca. 54 to $56 \mathrm{Mb}$ and 46 to $51 \mathrm{Mb}$, respectively.

There was no significant differences in fruit form between the two reciprocal cross groups ( $p$-value $=0.81)$. Thus the plastids from either parent did not differ regarding their effect on fasciation.

\section{Discussion}

We identified a novel QTL for blossom-end rot in tomato on chromosome 11. This QTL confirms previous observations (Ho et al. 1995) that the disposition for BER is genetically controlled. In our population the right genetic selection could lead to about $20 \%$ less affected fruits. However, since there was no significant difference between the parents of the RIL population in BER, the genetic background seems to play a role as well. The only other genetic region described to influence BER in tomato is on chromosome 8: a Solanum pennellii introgression line on this chromosome showed ca. 5\% BER compared to ca. $30 \%$ in the S. lycopersicum parent (Uozumi et al. 2012). The QTL we discovered was present in both light conditions.

In the compartment with LED supplemental lighting we observed less BER compared to supplemental HPS. Lower far red lighting under the 95\% red and 5\% blue LEDs compared to the HPS lamps could be one factor (ca. 5\% of far red light, 700-800 nm wavelength, was measured in the spectrum of the HPS lamps and hardly any detectable contribution in the LED lamps), though the mechanism underlying the light effect is not clear (Gruda and Tanny 2014). However, also other factors like canopy structure could play a role, as e.g. the internode length was smaller under LED light, and the stems of the plants were bending more outward (Supplemental Fig. 4). Also heat radiation (HPS lamps are warmer and heat plants more from above) could influence the microclimate favourably to reduce BER under LED compared to HPS supplemental lit compartment. Under HPS lamps there was more near infra-red and heat radiation on the plant which likely resulted in more transpiration (Dueck et al. 2012), and hence more water uptake. This may have led to the slightly higher EC found in the stone woll slabs in the HPS compartment. Higher EC was in other studies associated with a higher BER (Ieperen 1996; Peet 2009).
Mutwiwa et al (2008) found that blocking near infrared radiation lowered BER. They assumed that this effect is due to lowered temperature in the greenhouse and thereby lowered transpiration. Lower leaf transpiration could favour water and thereby calcium supply to the fruits and like this reduce BER (Balate et al. 2018) instead of to the higher transpiring leaves.

On average the Brix in the compartment with LED light was lower than the one with HPS supplemental lighting. This is in contrast with findings of Park et al. (2016) who found no difference between those two supplemental lighting systems. Park et al. (2016) used LEDs with a different spectrum (Red Blue White: $7: 2: 1)$ and the supplemental lights extended the light period, $3 \mathrm{~h}$ extra light after sunset and $2 \mathrm{~h}$ before sunrise. In our study the supplemental lights were on for $16 \mathrm{~h}$, adding depending on the day on average approximately $8 \mathrm{~h}$ of extra light before sunrise. The more extended light use in our setup may explain the difference between the experiments. In contrast to the LED lamps, the HPS lamps emit still a considerable amount of far red light which could be favouring a higher Brix (Kim et al. 2020). Supplemental far red light was found to reduce tomato fruit water content and promote biomass allocation to reproductive organs (Kim et al. 2019; Ji et al. 2020). However, the effect on Brix could also be caused indirectly by the light through a difference in plant temperature and transpiration. The presumably from increased transpiration resulting slightly higher $\mathrm{EC}$ in the stone wool slab under HPS lighting could result in a higher Brix of the fruit (Wu et al. 2004).

We report here on the first QTL for Brix, i.e. on chromosome 6, which was specifically identified in the LED light compartment. The parent of the RIL population, of which the allele confers a higher Brix in LED light, was 'Kentucky Beefsteak'. The parent, 'Kentucky Beefsteak', itself had a lower Brix than 'Ailsa Craig' but also showed less response to LED. Plants with a combination of 'Kentucky Beefsteak' at this locus and the 'Ailsa Craig' allele at the lightindependent QTL on chromosome 2 could reach the same level of Brix under LED as the average population had under HPS. This may be population dependent, however, our research indicates that breeding for Brix under LED light may be useful to keep identical quality under this new lighting environment. QTL for Brix on chromosome 2 (Lecomte et al. 2004) and 6 
(Paterson et al. 1990) were described before in other tomato genotypes. Therefore, it is possible that our findings do not only describe a rare allele but a more commonly present genetic basis.

Carbohydrate production is driven of course by photosynthesis and thereby the chloroplast genome could also influence Brix, so we also looked at plastid inherited genetic effects. However, neither BER nor Brix were significantly influenced in our population by the reciprocal cross group, so no significant differences were found between the effect from the maternally inherited plastids from the parents. Breeding for those traits may therefore be done independent of using a parent as mother or as father.

We detected QTL for fasciation of the fruits on chromosomes 2 and 11. This is consistent with earlier findings as the gene locule number $(L C)$ is located on chromosome 2 and fasciated (FAS) on chromosome 11 (Rodríguez et al. 2011; Sacco et al. 2015).

Due to the size and time of the experiment, replications in different years were not feasible. Therefore, the environmental component of our experimental setup was not replicated, as all plants from the same light circumstances were grown together in one greenhouse at the same time. We therefore cannot rule out that our identified phenotypes could be different between years or significantly different between greenhouses (e.g. larger production greenhouses). Apart from the light treatments the glasshouse compartments were very comparable, as both greenhouse compartments were next to each other, being treated in the same way, and receiving the same incoming solar.

The shown genetic components for BER and the LED specific QTL for could be the start for following breeding programs.

\section{Conclusion}

We showed a substantial reduction of the fruit quality traits Brix and BER in the greenhouse compartment with LED compared to HPS supplemental lighting. For both, Brix and BER, we identified involved genetic regions. Both genetic and environmental effects influenced the occurrence and severity of BER. Therefore, a combination of breeding and environmental approach to reduce BER seems a good strategy to reduce the future impact of this fruit disorder. For Brix the genetic basis in our experiment was depending on the light condition. Our data suggests that breeding for plants with a higher Brix specifically under LED light growing conditions may be possible.

Acknowledgements We thank Cees Schuit, Joost Baars, Frank Millenaar, Corine de Groot, Céline C. S. Nicole, Maarten Verlaan, Maaike Wubs from the involved companies for discussions. We thank Nunhems for developing and genotyping of the RIL population and Signify for the LED lamps and the respective light plan. For help in the greenhouse we thank Maarten Peters, André Maassen, Sean Geurts, Geurt Versteeg, Ad Hermsen and Rohan van Genderen. We further thank for advise and help the following colleagues at Wageningen University \& Research: Fien Meijer-Dekens, Jasper Vermeulen, Maarten Wassenaar, Johan Bucher, Julia van Oord, Nicole Trefflich-Luit, Joke Oosterkamp, Herman Meurs, Anton Vels, Erik Schuiling and Tijmen Kerstens.

Author contributions Aina Prinzenberg planned, conducted and analysed the RIL experiments and wrote the first draft of the manuscript; Hanneke van der Schoot helped with the planning of the RIL experiments and the measurements; Leo Marcelis, Richard Visser, Ep Heuvelink and Henk Schouten initiated the project and contributed with discussions. All authors contributed to varying degrees in the writing of the manuscript.

Funding Funded by the Netherlands Organisation of Scientific Research (NWO): project number 14211. This research is part of the NWO- Toegepaste en Technische Wetenschappen (TTW) "LED it be 50\%" program, supported by Bejo Zaden B.V., Glastuinbouw Nederland, Nunhems Netherlands B.V. (BASF), Rijk Zwaan Nederland B.V. and Signify B.V.

Availability of data and material Raw data in made available.

\section{Declartions}

Conflict of interest There are no conflicts of interest.

Open Access This article is licensed under a Creative Commons Attribution 4.0 International License, which permits use, sharing, adaptation, distribution and reproduction in any medium or format, as long as you give appropriate credit to the original author(s) and the source, provide a link to the Creative Commons licence, and indicate if changes were made. The images or other third party material in this article are included in the article's Creative Commons licence, unless indicated otherwise in a credit line to the material. If material is not included in the article's Creative Commons licence and your intended use is not permitted by statutory regulation or exceeds the permitted use, you will need to obtain permission directly from the copyright holder. To view a copy of this licence, visit http://creativecommons.org/licenses/by/4.0/. 


\section{References}

Adams P, Ho LC (1993) Effects of environment on the uptake and distribution of calcium in tomato and on the incidence of blossom-end rot. Plant Soil 154:127-132

Balate CA, de Souza DC, Resende LV et al (2018) Effect of abscisic acid on the calcium content for controlling blossom-end rot in tomato under water stress. Pesqui Agropecu Trop 48:414-419. https://doi.org/10.1590/198340632018v4852048

Baxter CJ, Carrari F, Bauke A et al (2005) Fruit carbohydrate metabolism in an introgression line of tomato with increased fruit soluble solids. Plant Cell Physiol 46:425-437. https://doi.org/10.1093/pcp/pci040

Britton CM, Dodd JD (1976) Relationships of photosynthetically active radiation and shortwave irradiance. Agric Meteorol 17:1-7. https://doi.org/10.1016/00021571(76)90080-7

Broman K, Sen S (2009) A Guide to QTL Mapping with R/qtl. Springer-Verlag, New York

Broman KW, Wu H, Sen Ś, Churchill GA (2003) R/qtl: QTL mapping in experimental crosses. Bioinformatics 19:889-890. https://doi.org/10.1093/bioinformatics/ btg 112

Djangsou H, Francia E, Ronga D, Buti M (2019) Blossom endrot in tomato (Solanum lycopersicum L.): a multi-disciplinary overview of inducing factors and control strategies. Sci Hortic 249:49-58. https://doi.org/10.1016/j.scienta. 2019.01.042

Dueck TA, Janse J, Eveleens BA et al (2012) Growth of tomatoes under hybrid led and HPS lighting. Acta Hortic 952:335-342. https://doi.org/10.17660/ActaHortic.2012. 952.42

Dzakovich MP, Gómez C, Mitchell CA (2015) Tomatoes grown with light-emitting diodes or high-pressure sodium supplemental lights have similar fruit-quality attributes. HortScience 50:1498-1502. https://doi.org/10.21273/ HORTSCI.50.10.1498

Fan M, Bie Z, Krumbein A, Schwarz D (2011) Salinity stress in tomatoes can be alleviated by grafting and potassium depending on the rootstock and K-concentration employed. Sci Hortic 130:615-623. https://doi.org/10.1016/j.scienta. 2011.08.018

Fox J, Weisberg S (2019) An R companion to applied regression, 3rd edn. SAGE Publications Inc, Thousand Oaks, USA (CA)

Franco JA, Pérez-Saura PJ, Ndez JAF et al (1999) Effect of two irrigation rates on yield, incidence of blossom-end rot, mineral content and free amino acid levels in tomato cultivated under drip irrigation using saline water. J Hortic Sci Biotechnol 74:430-435. https://doi.org/10.1080/ 14620316.1999.11511132

Gruda N, Tanny J (2014) Protected crops. Horticulture: plants for people and places, vol 1. Springer, Dordrecht, The Netherlands, pp 327-405

Haydar AT, Islam RS (2007) Heterosis, combining ability and genetics for brix\%, days to first fruit ripening and yield in tomato (Lycopersicon esculentum Mill.). Middle-East J Sci Res 2:128-131
Helyes L, Lugasi A (2006) Formation of certain compounds having technological and nutritional importance in tomato fruits during maturation. Acta Aliment 35:183-193. https:// doi.org/10.1556/aalim.35.2006.2.5

Helyes L, Pék Z, Lugasi A (2008) Function of the variety technological traits and growing conditions on fruit components of tomato (Lycopersicon Lycopersicum L. Karsten). Acta Aliment 37:427-436. https://doi.org/10.1556/ AAlim.2008.0010

Helyes L, Lugasi A, Pék Z (2012) Effect of irrigation on processing tomato yield and antioxidant components. Turkish J Agric for 36:702-709. https://doi.org/10.3906/tar-1107-9

Ho LC, Belda R, Brown M et al (1993) Uptake and transport of calcium and the possible causes of blossom-end rot in tomato. J Exp Bot 44:509-518. https://doi.org/10.1093/ $\mathrm{jxb} / 44.2 .509$

Ho LC, Adams P, Li XZ et al (1995) Responses of Ca-efficient and Ca-inefficient tomato cultivars to salinity in plant growth, calcium accumulation and blossom-end rot. J Hortic Sci 70:909-918. https://doi.org/10.1080/ 14620316.1995.11515366

Ho LC, Hand DJ, Fussell M (1999) Improvement of tomato fruit quality by calcium nutrition. Acta Hortic 481:463-468. https://doi.org/10.17660/ActaHortic.1999.481.53

Ieperen WV (1996) Effects of different day and night salinity levels on vegetative growth, yield and quality of tomato. J Hortic Sci 71:99-111. https://doi.org/10.1080/14620316. 1996.11515386

Ikeda H, Kanayama Y (2015) Blossom-End Rot in Fruit Vegetables. Abiotic Stress Biology in Horticultural Plants. Springer, Tokyo, Japan, pp 117-126

Ikeda H, Hiraga M, Shirasawa K et al (2013) Analysis of a tomato introgression line, IL8-3, with increased brix content. Sci Hortic 153:103-108. https://doi.org/10.1016/j. scienta.2013.02.006

Ji Y, Ocaña DN, Choe D et al (2020) Far-red radiation stimulates dry mass partitioning to fruits by increasing fruit sink strength in tomato. New Phytol Press: https://doi.org/10. 1111/nph.16805

Kim H-J, Lin M-Y, Mitchell CA (2019) Light spectral and thermal properties govern biomass allocation in tomato through morphological and physiological changes. Environ Exp Bot 157:228-240. https://doi.org/10.1016/j. envexpbot.2018.10.019

Kim H-J, Yang T, Choi S et al (2020) Supplemental intracanopy far-red radiation to red LED light improves fruit quality attributes of greenhouse tomatoes. Sci Hortic 261:108985. https://doi.org/10.1016/j.scienta.2019.108985

Latifah E, Handoko MR (2020) The effects of rootstock and water logging duration on calcium absorption and the rotting of the bottom fruit (blossom end rot) of tomato plant (Solanum lycopersicun L.) cervo varieties. Russian J Agric Socio-Econ Sci 97:126-132. https://doi.org/10.18551/ rjoas.2020-01.16

Lecomte L, Saliba-Colombani V, Gautier A et al (2004) Fine mapping of QTLs of chromosome 2 affecting the fruit architecture and composition of tomato. Mol Breed 13:1-14. https://doi.org/10.1023/B:MOLB.0000012325. $77844.0 \mathrm{c}$

Lo C, Manurung R, Rachmi Esyanti R (2014) Enhancement of lycopene and $\mathrm{B}$-carotene production in cherry tomato fruits 
(Solanum lycopersicum L. var. cerasiforme) by using red and blue light treatment. Int J Tech Res Appl 2:7-10

McCree KJ (1972) The action spectrum, absorptance and quantum yield of photosynthesis in crop plants. Agric Meteorol 9:191-216. https://doi.org/10.1016/00021571(71)90022-7

Mendiburu De F (2020) agricolae: statistical procedures for agricultural aesearch. https://CRAN.R-project.org/ package $=$ agricolae

Mestre TC, Garcia-Sanchez F, Rubio F et al (2012) Glutathione homeostasis as an important and novel factor controlling blossom-end rot development in calcium-deficient tomato fruits. J Plant Physiol 169:1719-1727. https://doi.org/10. 1016/j.jplph.2012.07.013

Mutwiwa U, von Elsner B, Max J et al (2008) Effects of NIRreflection greenhouse cooling on blossom-end rot and fruit cracking in tomato (Solanum lycopersicum L). African J Hortic Sci 1:33-43

Olle M, Williams IH (2017) Physiological disorders in tomato and some methods to avoid them. J Hortic Sci Biotechnol 92:223-230. https://doi.org/10.1080/14620316.2016. 1255569

Paponov M, Kechasov D, Lacek J et al (2020) Supplemental light-emitting diode inter-lighting increases tomato fruit growth through enhanced photosynthetic light use efficiency and modulated root activity. Front Plant Sci. https:// doi.org/10.3389/fpls.2019.01656

Park YH, Seo BS, Seo JB et al (2016) Effects of supplemental light on quality, yield, and growth rate of tomatoes. Acta Hort 1129:105-110

Paterson AH, DeVerna JW, Lanini B, Tanksley SD (1990) Fine mapping of quantitative trait loci using selected overlapping recombinant chromosomes, in an interspecies cross of tomato. Genetics 124:735-742

Peet MM (2009) Physiological disorders in tomato fruit development. Acta Hortic. https://doi.org/10.17660/ActaHortic. 2009.821.16

Rodríguez GR, Muños S, Anderson C et al (2011) Distribution of SUN, OVATE, LC, and FAS in the tomato germplasm and the relationship to fruit shape diversity. Plant Physiol 156:275-285. https://doi.org/10.1104/pp.110.167577

Sacco A, Ruggieri V, Parisi M et al (2015) Exploring a tomato landraces collection for fruit-related traits by the aid of a high-throughput genomic platform. PLoS ONE 10:e0137139. https://doi.org/10.1371/journal.pone. 0137139

Saure MC (2001) Blossom-end rot of tomato (Lycopersicon esculentum Mill.)-a calcium- or a stress-related disorder? Sci Hortic 90:193-208. https://doi.org/10.1016/S03044238(01)00227-8

Sen S, Churchill GA (2001) A statistical framework for quantitative trait mapping. Genetics 159:371-387

Tachibana S (1991) Import of calcium by tomato fruit in relation to the day-night periodicity. Sci Hortic 45:235-243. https:// doi.org/10.1016/0304-4238(91)90068-A

Uozumi A, Ikeda H, Hiraga M et al (2012) Tolerance to salt stress and blossom-end rot in an introgression line, IL8-3, of tomato. Sci Hortic 138:1-6. https://doi.org/10.1016/j. scienta.2012.01.036

Wickham H (2016) ggplot2: elegant graphics for data analysis. Springer Publishing, New York

Wu M, Buck JS, Kubota C (2004) Effects of nutrient solution $\mathrm{EC}$, plant micoclimate and cultivars on fruit quality and yield of hydroponic tomatoes (Lycopersicon esculentum). Acta Hortic. https://doi.org/10.17660/ActaHortic.2004. 659.70

Zhai Y, Yang Q, Hou M (2015) The effects of saline water drip irrigation on tomato yield, quality, and blossom-end rot incidence-A 3a case study in the south of China. PLoS ONE 10:e0142204. https://doi.org/10.1371/journal.pone. 0142204

Publisher's Note Springer Nature remains neutral with regard to jurisdictional claims in published maps and institutional affiliations. 